\title{
鄂西南两个自然保护区亚热带常绿落叶阔叶混交 林类型及其常绿和落叶物种组成结构分析
}

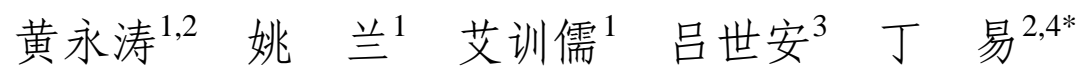

${ }^{1}$ 湖北民族学院林学园艺学院, 湖北恩施 445000; ${ }^{2}$ 中国林业科学研究院森林生态环境与保护研究所, 北京 $100091 ;{ }^{3}$ 湖北星斗山国家级自然保护区, 湖北恩施 445000; ${ }^{4}$ 南京林业大学南方现代林业协同创新中心, 南京 210037

摘 要 为深入研究亚热带常绿落叶阔叶混交林的生物多样性维持机制, 合理保护与利用此类森林植被, 以鄂西南两个自然 保护区一一星斗山和木林子典型的亚热带常绿落叶阔叶混交林为研究对象, 在野外样方调查的基础上进行了群落数量分类 和排序, 分析了常绿和落叶物种比例随群落类型及环境因子变化的规律。研究结果表明: (1)将鄂西南两个自然保护区的亚热 带常绿落叶阔叶混交林划分为 5 个群落类型: 即青冈-翅柃+尖连蒿茶(Cyclobalanopsis glauca-Eurya alata + Camellia cuspidata) 群落(I)、川陕鹅耳枥+青冈-翅柃(Carpinus fargesiana + Cyclobalanopsis glauca-Eurya alata)群落(II)、川陕鹅耳枥+青冈-水马桑 (Carpinus fargesiana + Cyclobalanopsis glauca-Weigela japonica)群落(III)、光叶水青冈+多脉青冈-翅柃(Fagus lucida + Cyclobalanopsis multinervis-Eurya alata)群落(IV)和川陕鹅耳枥+交让木+包果柯-翅柃(Carpinus fargesiana + Daphniphyllum macropodum + Lithocarpus cleistocarpus-Eurya alata)群落(V); (2)常绿和落叶物种的丰富度、多度、胸高断面积及重要值等指 标随群落类型而变化。在群落II、III和V中落叶物种占优势, 而在群落I和IV中二者无显著差异; (3)各类型群落在小径级 $(1-5$ $\mathrm{cm})$ 内落叶物种的丰富度大于常绿物种, 但多度、胸高断面积和重要值大都小于常绿物种。在中径级 (5-10 cm)内, 群落I和群 落IV的各项指标都表现为常绿物种大于落叶物种, 而群落II、群落III和群落 $\mathrm{V}$ 的则相反。在大径级 $(\geqslant 10 \mathrm{~cm})$ 内, 各群落类型 的落叶物种都占显著优势, 其各项指标大于常绿物种; (4)海拔、坡度、坡向、土壤氮含量和土壤磷含量是影响各群落类型内 常绿和落叶物种比例变化的主导因子。

关键词＼cjkstart群落类型, 常绿落叶阔叶混交林, 环境因子, 常绿落叶物种比例, 数量分类

引用格式: 黄永涛, 姚兰, 艾训儒, 吕世安, 丁易 (2015). 鄂西南两个自然保护区亚热带常绿落叶阔叶混交林类型及其常绿和落叶物种组成结构分析. 植物生态学报, 39, 990-1002. doi: 10.17521/cjpe.2015.0096

\section{Quantitative classification of the subtropical evergreen-deciduous broadleaved mixed forest and the deciduous and evergreen species composition structure across two national nature reserves in the southwest of Hubei, China}

HUANG Yong-Tao ${ }^{1,2}$, YAO Lan ${ }^{1}$, AI Xun-Ru ${ }^{1}$, LÜ Shi-An ${ }^{3}$, and DING Yi ${ }^{2,4^{*}}$

${ }^{1}$ School of Forestry and Horticulture, Hubei University for Nationalities, Enshi, Hubei 445000, China; ${ }^{2}$ Institute of Forest Ecology, Environment and Protection, Chinese Academy of Forestry, Beijing 100091, China; ${ }^{3}$ Xingdoushan National Nature Reserve, Enshi, Hubei 445000, China; and ${ }^{4}$ Collaborative Innovation Center of Sustainable Forestry in Southern China, Nanjing Forestry University, Nanjing 210037, China

\section{Abstract}

Aims The subtropical evergreen-deciduous broadleaved mixed forest is the largest extant natural vegetation type in southwest Hubei. However, little knowledge exists on the types and compositions (especially the relative ratios of evergreen versus deciduous species) of this forest vegetation. Here, we quantitatively classify the less studied forest vegetation into different community types, compare their size and composition structure, and analyze species-environment relationships which is the basis for further understanding the biodiversity maintenance mechanism and reasonable protection and utilization of this forest.

Methods We established $9220 \mathrm{~m} \times 20$ m plots of subtropical evergreen-deciduous broadleaved mixed forest in two national nature reserves in Enshi, Hubei Province, China. All species with stems $\geqslant 1 \mathrm{~cm}$ diameter at breast height $(D B H)$ in each plot were identified and mapped. These plots were classified by using two-way indicator species analysis (TWINSPAN) and detrended correspondence analysis (DCA). The species richness, abundance, basal area and importance value were chosen to compare structure, species composition and evergreen and

收稿日期Received: 2015-02-13 接受日期Accepted: 2015-07-23

* 通讯作者Author for correspondence (E-mail: ydingcaf@163.com) 
deciduous ratio. Permutation-based multiple regression on distance matrices and multiple stepwise regression analysis were used to examine the relationship between species distribution and environmental factors.

Important findings Our results showed that the subtropical evergreen-deciduous broadleaved mixed forest in the southwest of Hubei could be classified into five community types based on quantitative methods: i.e. Cyclobalanopsis glauca-Eurya alata + Camellia cuspidate (community type I), Carpinus fargesiana + Cyclobalanopsis glauca-Eurya alata (community type II), Carpinus fargesiana + Cyclobalanopsis glauca-Weigela japonica (community type III), Fagus lucida + Cyclobalanopsis multinervis-Eurya alata (community type IV) and Carpinus fargesiana + Daphniphyllum macropodum + Lithocarpus cleistocarpus-Eurya alata (community type V). Species richness, abundance, basal area and importance value of evergreen and deciduous species in each community types were different. Deciduous species in community II, community III and community V were significantly higher than evergreen species in terms of species richness, stem abundance, basal area and importance value, but they had no significant differences in community I and community IV. The richness of deciduous species in most community types were higher than those of evergreen species, meanwhile the abundance, basal area and importance value of deciduous species in the small size classes $(1 \mathrm{~cm} \leqslant D B H<5 \mathrm{~cm})$ in each community types were lower than those of evergreen species. In middle size classes $(5 \mathrm{~cm} \leqslant D B H<10 \mathrm{~cm}$ ), the richness, abundance, basal area and importance value of deciduous species were higher than those of evergreen species in community II, community III and community V. However, in community I and community IV, the evergreen species were larger than deciduous species in the four indexes. The richness of deciduous species in majority of the community types were higher than those of evergreen species in large size classes $(D B H \geqslant 10 \mathrm{~cm})$. The elevation, slope and aspect, soil total nitrogen content, soil total phosphorus content, soil available nitrogen content and soil available phosphorus content were the major factors affecting evergreen and deciduous species distribution across the five community types.

Key words community type, the evergreen-deciduous broadleaved mixed forest, environmental factors, ratio of deciduous and evergreen species, quantitative classification

Citation: Huang YT, Yao L, Ai XR, Lü SA, Ding Y (2015). Quantitative classification of the subtropical evergreen-deciduous broadleaved mixed forest and the deciduous and evergreen species composition structure across two national nature reserves in the southwest of Hubei, China. Chinese Journal of Plant Ecology, 39, 990-1002. doi: 10.17521/cjpe.2015.0096

常绿落叶阔叶混交林是一种介于落叶阔叶林与 常绿榈叶林之间的森林植被类型, 通常被认为是与 常绿阔叶林和落叶阔叶林并列的一种植被类型(吴 中伦, 2000), 并可进一步划分为不同的植被亚型(吴 征镒, 1980)。目前对常绿落叶阔叶混交林自然分布 的划定和分类存在不同观点 (吴征镒, 1980; 安树青 等, 1998; 宋永昌, 1999; 方精云, 2001)。长期以来, 我国对常绿落叶阔叶混交林的基本概念(班继德和 漆根深, 1995; 周光裕, 1996)、空间分布(沈泽昊和方 精云, 2001; 张烅等, 2004)、物种组成(曹铁如等, 1997; 汪正祥等, 2006; 赵丽娟等, 2013)、群落更新 (熊小刚等, 2002; 汤景明等, 2010; 刘海波等, 2014)、种间关系(韩文衡等, 2009)、外来种入侵(卢 少飞等, 2005)和珍稀物种分布(沈泽昊等, 1999)等方 面有了一定的研究。然而, 相对于典型的常绿阔叶 林和落叶阔叶林生态研究来说, 亚热带常绿落叶阔 叶混交林及其生态特征的研究还非常薄弱。

湖北西南部地区是湖北重要的天然林分布区,
亚热带常绿阔叶林为该地区的地带性植被。随着海 拔的升高, 含有落叶成分的亚热带常绿落叶阔叶混 交林逐步成为优势植被。亚热带常绿落叶阔叶混交 林植物区系成分复杂, 生物多样性丰富, 不仅为我 国的经济建设提供了大量的优质木材和林副产品, 而且对我国特有的古老子遗物种保护、维护区域生 态平衡发挥着重要的作用(汤景明等, 2010)。由于气 候、地质和区域物种库等方面的差异，不同区域的 常绿落叶阔叶混交林具有不同的变化特征, 针对不 同区域的森林植被开展相关的生态学研究显得尤为 必要。对亚热带常绿落叶阔叶混交林的群落类型进 行科学划分, 不仅有助于我们对现存森林植被基本 特征的认识, 而且是我们进一步深入开展生态系统 功能与生态过程研究的基础。了解常绿和落叶物种 比例随群落类型的变化规律, 能够揭示不同群落中 环境条件对物种分布的影响, 从而为我们阐明生物 多样性维持与调控机制奠定基础。亚热带常绿落叶 阔叶混交林的群落类型及组成结构的研究是对其进 
行有效地保育、可持续经营与合理利用的科学基础。

本研究以鄂西南星斗山和木林子自然保护区亚 热带常绿落叶阔叶混交林为研究对象, 在建立系列 森林动态固定样地的基础上, 对该地区的植物群落 进行了数量分类与排序, 探讨植被与环境之间的关 系, 并分析常绿和落叶物种随不同群落类型及环境 条件的变化, 以期为深入研究亚热带常绿落叶阔叶 混交林的生物多样性与生态功能维持机制, 合理保 护与利用此类森林植被提供科学依据。

\section{1 研究区概况}

研究地点位于湖北恩施的星斗山国家级自然保 护区和木林子国家级自然保护区。以上 2 个保护区是 鄂西南天然森林植被保存最为完好的区域, 是鄂西 南现存天然森林植被的典型代表。

星斗山国家级自然保护区位于鄂西南恩施、利 川与咸丰三县(市、州)交界处, 地理坐标 $29.95^{\circ}$ $30.17^{\circ} \mathrm{N}, 108.95^{\circ}-109.45^{\circ} \mathrm{E}$ 。是齐岳山向东北的延 伸部分, 因有大巴山系巫山余脉作屏障, 成为第三 纪植物的“避难所”。海拔672-1 $751 \mathrm{~m}$ 。雨量充沛, 气 候温和, 年平均气温 $12.8^{\circ} \mathrm{C}$, 年降水量 $1200-1400$ $\mathrm{mm}$, 无霜期 234 天, 相对湿度 $85 \%$ 左右。土壤以山地 黄壤、黄棕壤、棕壤为主(艾训儒和谭建锡, 1999; 方 元平和刘胜祥, 2006)。

湖北木林子国家级自然保护区位于湖北省恩施 土家族苗族自治州鹤峰县境内, 地理坐标 $29.21^{\circ}-$ $30.17^{\circ} \mathrm{N}, 109.98^{\circ}-110.81^{\circ} \mathrm{E}$ ，海拔1 100.0-2 095.6 $\mathrm{m}$, 属武陵山脉北支余脉, 地势由西北和东南向中 间逐渐倾斜。该区属于亚热带季风性湿润气候, 雨 热同期, 时空分布不均, 年降水量1 $733 \mathrm{~mm}$, 春秋 多阴雨, 夏季雨量较多, 冬季雨少雾多, 蒸发小, 湿 度大, 年平均相对湿度为 $82 \%$, 无霜期 $270-279$ 天。 年平均气温为 $15.5{ }^{\circ} \mathrm{C}$, 最冷月 $(1$ 月)平均气温为 4.6 ${ }^{\circ} \mathrm{C}$, 最热月(7月)平均气温为 $26{ }^{\circ} \mathrm{C}$ 。土壤以黄棕壤、 棕壤、黄壤为主(葛继稳等, 2009)。

\section{2 研究方法}

\section{1 固定样地的建立与调查}

2013年9月-2014年6月, 在湖北星斗山自然保 护区和湖北木林子自然保护区的典型天然森林植被 中, 分别随机设置永久性森林动态样地 45 个和 47 个, 每个样地面积均为 $20 \mathrm{~m} \times 20 \mathrm{~m}$ 。这些样地分布于海
拔1 248-1 800 m之间。样地建设采用CTFS森林动态 样地监测标准(Condit, 1998)。在每个样地中利用网 格法将其分割成 16 个 $5 \mathrm{~m} \times 5 \mathrm{~m}$ 的小样方, 在小样方 内对所有胸径 $\geqslant 1 \mathrm{~cm}$ 的乔木、灌木和藤本进行编号、 测量点刷漆标记并开展每木检尺, 记录内容包括物 种名称、胸径、坐标、萌生与死亡状况, 同时记录 样地所在坡度、海拔、调落物厚度。

\section{2 常绿和落叶物种的确定}

常绿和落叶物种的划分主要通过查阅《湖北植 物志》(傅书遐，2002)及咨询植物分类专家来确定， 对于那些不明确的物种, 由作者在冬季进行实地观 测和采访当地林业工作者获得。

\section{3 数据处理}

坡向以正北为起点 $\left(0^{\circ}\right)$, 采用顺时针旋转的角 度表示, 数字等级划分为: 1 表示阴坡 $\left(0^{\circ}-45^{\circ}\right.$ 和 $\left.315^{\circ}-360^{\circ}\right), 2$ 表示半阴坡 $\left(45^{\circ}-90^{\circ}\right.$ 和 $\left.270^{\circ}-315^{\circ}\right), 3$ 表 示半阳坡 $\left(90^{\circ}-135^{\circ}\right.$ 和 $\left.225^{\circ}-270^{\circ}\right), 4$ 表示阳坡 $\left(135^{\circ}-225^{\circ}\right)$, 数值越大, 表示光照越多。土壤因子的 测定方法为: 土壤 $\mathrm{pH}$ 值用电位法、土壤有机质用重 铬酸钾容量法、土壤碱解 $\mathrm{N}$ 用碱解扩散法、速效 $\mathrm{P}$ 用 双酸法浸提-钼锑抗比色法、全N用半微量凯氏定氮 法、全P用硫酸-高氯酸消解法。

以样地为单位分别计算物种的重要值, 计算公 式为: 重要值 $(I V)=($ 相对多度 + 相对显著度 + 相对频 度)/3。采用VEAPAN软件包中的TWINSPAN进行群 落分类; 通过CANOCO 4.5软件(张金屯, 1995)对样 地和物种的重要值矩阵进行DCA排序。根据个体胸 径 $(D B H)$ 将物种划分为 3 个等级: 小径级 $(1 \mathrm{~cm} \leqslant$ $D B H<5 \mathrm{~cm})$ 、中径级 $(5 \mathrm{~cm} \leqslant D B H<10 \mathrm{~cm})$ 和大径 级 $(D B H \geqslant 10 \mathrm{~cm})$ 。基于Bray-Curtis相似距离, 采用 基于矩阵的多元回归分析(Permutation-based multiple regression on distance matrices, MRM)确定显著影响 群落物种组成变化的环境因子(Lichstein, 2007)。运用 多元逐步回归分析(multiple regression analysis)来分 析常绿和落叶物种与环境因子之间的关系。

使用R 3.1.1和Origin 8.5进行统计分析和作图。

\section{3 结果和分析}

\section{1 群落数量分类与排序}

应用TWINSPAN分类可将所调查的 92 个样地 分为 5 个群落类型(图1)。在DCA排序图(图2)中, DCA 前两轴的贡献率分别为 $56.7 \%$ 和 $29.8 \%$, 累计 


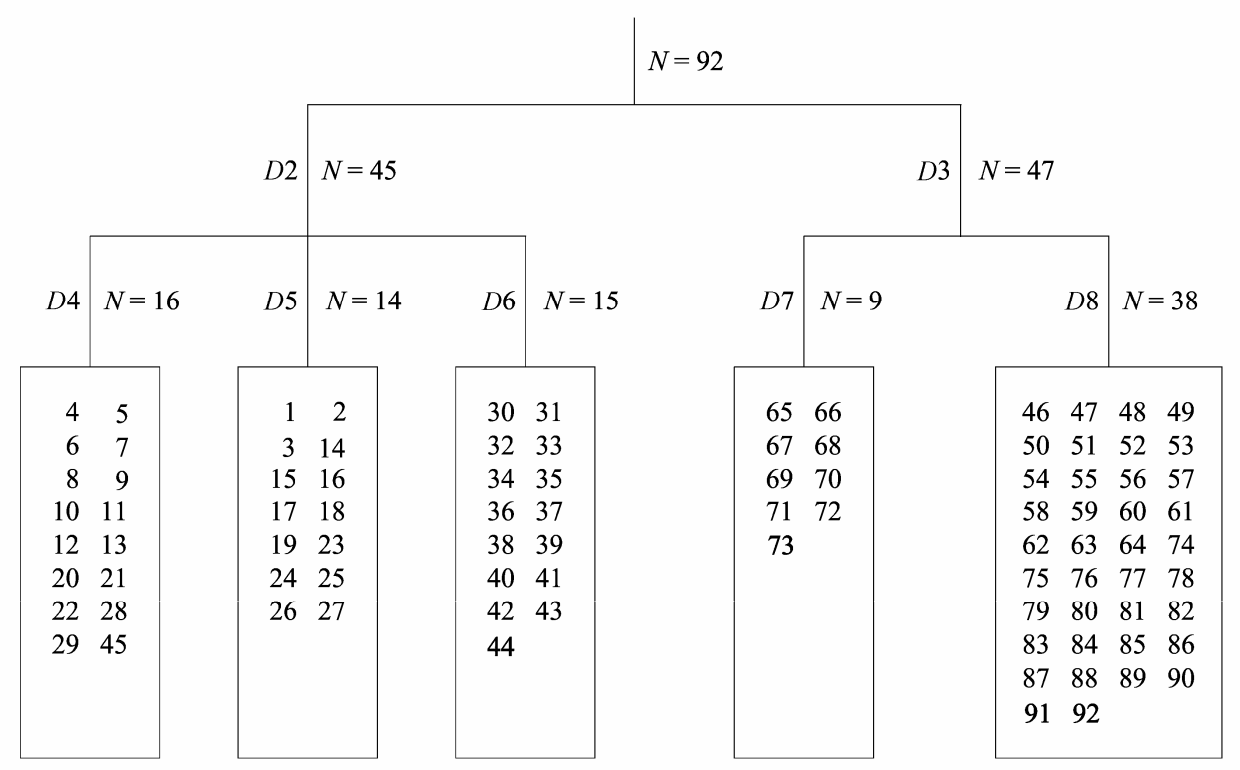

图1 鄂西南两个保护区亚热带常绿落叶阔叶混交林 92 个样地的TWINSPAN分类树状图。 $D$, 分类次数; $N$, 样方数。

Fig. 1 Dendrogram of TWINSPAN classification for 92 plots in the subtropical evergreen-deciduous broadleaved mixed forest across two nature reserves in Southwest Hubei, China. $D$, division number; $N$, number of plot.

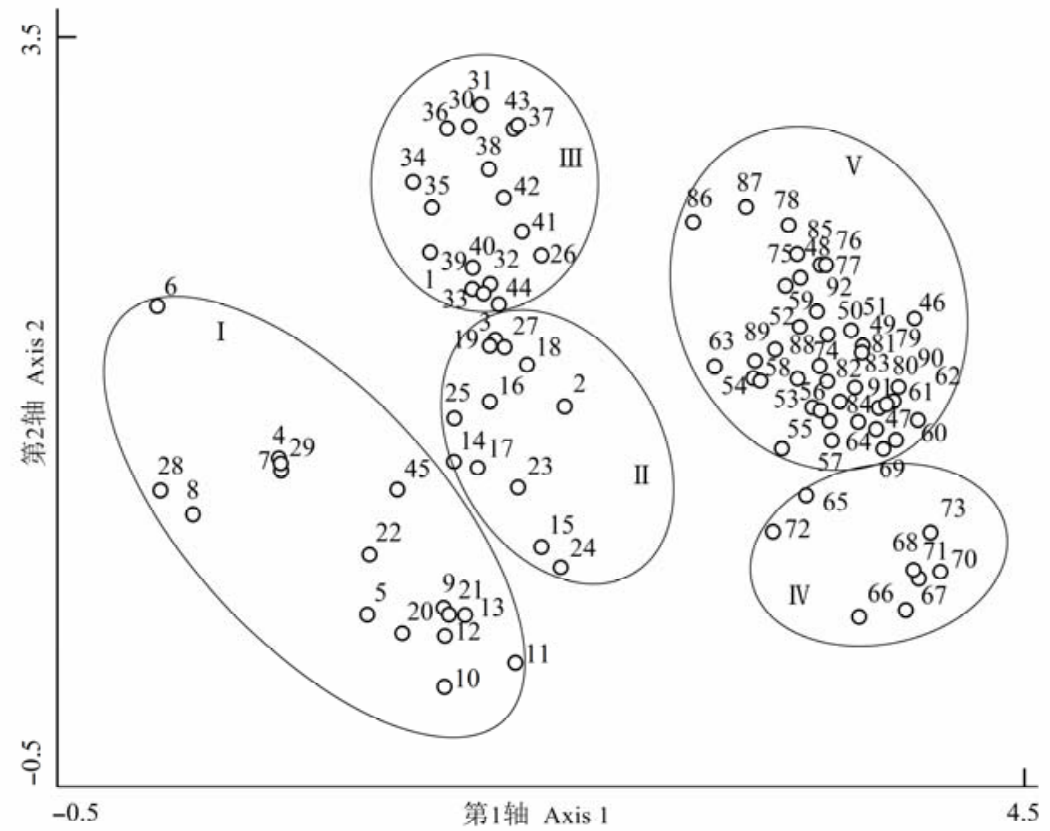

图2 鄂西南两个保护区亚热带常绿落叶阔叶混交林 92 个样地的DCA二维排序图。罗马数字(I, II, III, IV, V)代表不同的群落类型。

Fig. 2 Two-dimensional DCA ordination diagram for 92 plots in the subtropical evergreen-deciduous broadleaved mixed forest across two nature reserves in Southwest Hubei, China. Roman numerals (I, II, III, IV, V) indicate different community types.

贡献率达 $86.5 \%$ 。结合TWINSPAN分类与DCA排序 的结果, 可将鄂西南星斗山和木林子自然保护区亚 热带常绿落叶阔叶混交林的森林群落划分为 5 类, 其中木林子包括I (青冈-翅柃+尖连荵茶群落(Cyclobalanopsis glauca-Eurya alata + Camellia cuspidata ) )、II (川陕鹅耳枥+青冈-翅柃群落(Carpinus fargesiana + Cyclobalanopsis glauca-Eurya alata))和 III (川陕鹅耳枥+青冈-水马桑群落(Carpinus farge- siana + Cyclobalanopsis glauca-Weigela japonica) ) 3 个群落, 星斗山包括IV (光叶水青冈+多脉青冈-翅 柃群落(Fagus lucida + Cyclobalanopsis multinervisEurya alata) )和V (川陕鹅耳枥+交让木+包果柯-翅 柃群落(Carpinus fargesiana+Daphniphyllum macropodum + Lithocarpus cleistocarpus-Euryaalata)) 2 个 群落。各群落的主要物种组成见表1。各样地的物种 状况见附录1。 
表1鄂西南两个保护区亚热带常绿落叶阔叶混交林5种群落类型内重要值排名前10位的物种

Table 1 Importance value ( $I V$ ) of the top 10 species in the five community types in the subtropical evergreen-deciduous broadleaved mixed forest across two nature reserves in Southwest Hubei, China

\begin{tabular}{|c|c|c|c|c|c|}
\hline 群落类型 Community type & 物种 Species & 多度 Abundance & 胸径 $D B H(\mathrm{~cm})$ & 重要值 $I V$ & 叶习性 Leaf habit \\
\hline 群落I & 青冈 Cyclobalanopsis glauca & 752 & 6.38 & 2.48 & 常绿 Evergreen \\
\hline \multirow[t]{9}{*}{ Type I } & 翅柃 Eurya alata & 599 & 4.02 & 1.12 & 常绿 Evergreen \\
\hline & 尖连萝茶 Camellia cuspidata & 487 & 3.64 & 1.11 & 常绿 Evergreen \\
\hline & 木荷 Schima superba & 248 & 5.94 & 0.99 & 常绿 Evergreen \\
\hline & 山矾 Symplocos sumuntia & 535 & 3.05 & 0.95 & 常绿 Evergreen \\
\hline & 雉栗 Castanea henryi & 17 & 53.96 & 0.83 & 落叶 Deciduous \\
\hline & 黄丹木姜子 Litsea elongata & 385 & 2.85 & 0.82 & 常绿 Evergreen \\
\hline & 薄叶山矾 Symplocos anomala & 207 & 3.59 & 0.39 & 常绿 Evergreen \\
\hline & 茶条果 Symplocos phyllocalyx & 137 & 3.81 & 0.38 & 常绿 Evergreen \\
\hline & 四照花 Dendrobenthamia japonica & 70 & 7.58 & 0.36 & 落叶 Deciduous \\
\hline 群落II & 川陕鹅耳枥 Carpinus fargesiana & 669 & 4.05 & 1.28 & 落叶 Deciduous \\
\hline \multirow[t]{9}{*}{ Type II } & 山矾 Symplocos sumuntia & 1007 & 2.57 & 1.26 & 常绿 Evergreen \\
\hline & 青冈 Cyclobalanopsis glauca & 382 & 4.84 & 1.02 & 常绿 Evergreen \\
\hline & 四照花 Dendrobenthamia japonica & 367 & 3.9 & 0.84 & 落叶 Deciduous \\
\hline & 亮叶桦 Betula luminifera & 92 & 15.45 & 0.78 & 落叶 Deciduous \\
\hline & 翅柃 Eurya alata & 452 & 2.44 & 0.65 & 常绿 Evergreen \\
\hline & 水马桑 Weigela japonica & 172 & 4.51 & 0.40 & 落叶 Deciduous \\
\hline & 灯台树 Bothrocaryum controversum & 68 & 8.54 & 0.36 & 落叶 Deciduous \\
\hline & 黄丹木姜子 Litsea elongata & 136 & 3.13 & 0.34 & 常绿 Evergreen \\
\hline & 枫香树 Liquidambar formosana & 56 & 10.92 & 0.31 & 落叶 Deciduous \\
\hline 群落III & 川陕鹅耳枥 Carpinus fargesiana & 1108 & 4.03 & 1.63 & 落叶 Deciduous \\
\hline \multirow[t]{9}{*}{ Type III } & 水马桑 Weigela japonica & 843 & 3.89 & 1.41 & 落叶 Deciduous \\
\hline & 青冈 Cyclobalanopsis glauca & 850 & 3.93 & 1.18 & 常绿 Evergreen \\
\hline & 四照花 Dendrobenthamia japonica & 580 & 3.25 & 0.82 & 落叶 Deciduous \\
\hline & 灰柯 Lithocarpus henryi & 353 & 4.90 & 0.73 & 常绿 Evergreen \\
\hline & 亮叶桦 Betula luminifera & 144 & 9.80 & 0.72 & 落叶 Deciduous \\
\hline & 小叶青冈 Cyclobalanopsis myrsinifolia & 432 & 4.76 & 0.68 & 常绿 Evergreen \\
\hline & 盐肤木 Rhus chinensis & 163 & 7.14 & 0.57 & 落叶 Deciduous \\
\hline & 贵定桤叶树 Clethra cavaleriei & 355 & 3.11 & 0.57 & 落叶 Deciduous \\
\hline & 山鸡椒 Litsea cubeba & 344 & 3.08 & 0.57 & 落叶 Deciduous \\
\hline 群落IV & 光叶水青冈 Fagus lucida & 325 & 9.77 & 1.64 & 常绿 Evergreen \\
\hline \multirow[t]{9}{*}{ Type IV } & 多脉青冈 Cyclobalanopsis multinervis & 414 & 6.87 & 1.23 & 落叶 Deciduous \\
\hline & 翅柃 Eurya alata & 526 & 3.13 & 0.95 & 常绿 Evergreen \\
\hline & 川陕鹅耳枥 Carpinus fargesiana & 140 & 8.16 & 0.62 & 落叶 Deciduous \\
\hline & 宜昌润楠 Machilus ichangensis & 77 & 7.88 & 0.31 & 常绿 Evergreen \\
\hline & 交让木 Daphniphyllum macropodum & 72 & 7.12 & 0.28 & 常绿 Evergreen \\
\hline & 杜鹃 Rhododendron simsii & 196 & 2.11 & 0.20 & 常绿 Evergreen \\
\hline & 英蒾 Viburnum dilatatum & 119 & 2.04 & 0.20 & 落叶 Deciduous \\
\hline & 光叶山矾 Symplocos lancifolia & 60 & 4.28 & 0.17 & 常绿 Evergreen \\
\hline & 包果柯 Lithocarpus cleistocarpus & 48 & 7.69 & 0.17 & 常绿 Evergreen \\
\hline 群落V & 川陕鹅耳枥 Carpinus fargesiana & 1359 & 7.63 & 4.67 & 落叶 Deciduous \\
\hline \multirow[t]{9}{*}{ Type V } & 翅柃 Eurya alata & 1710 & 2.84 & 2.53 & 常绿 Evergreen \\
\hline & 包果柯 Lithocarpus cleistocarpus & 502 & 8.13 & 1.71 & 常绿 Evergreen \\
\hline & 交让木 Daphniphyllum macropodum & 461 & 5.08 & 1.53 & 常绿 Evergreen \\
\hline & 亮叶桦 Betula luminifera & 201 & 12.09 & 1.40 & 落叶 Deciduous \\
\hline & 齿缘吊钟花 Enkianthus serrulatus & 1268 & 3.03 & 1.37 & 落叶 Deciduous \\
\hline & 长荵杜鹃 Rhododendron stamineum & 854 & 3.29 & 1.17 & 常绿 Evergreen \\
\hline & 水马桑 Weigela japonica & 345 & 5.56 & 1.17 & 落叶 Deciduous \\
\hline & 雉栗 Castanea henryi & 145 & 16.32 & 1.16 & 落叶 Deciduous \\
\hline & 石灰花楸 Sorbus folgneri & 519 & 4.91 & 1.09 & 落叶 Deciduous \\
\hline
\end{tabular}

$\overline{D B H}$, diameter at breast height. $I V$, importance value. 
3.2 不同群落类型内常绿和落叶物种丰富度、多

\section{度、胸高断面积及重要值的变化}

在5个群落类型中，群落II、群落III和群落V内 落叶物种的物种丰富度显著大于常绿物种 $(p<$ 0.001) (图3A)。群落I与群落IV内常绿和落叶物种的 物种丰富度差异不显著 $(p>0.05)$ 。

群落I和群落III中常绿与落叶物种的多度存在 显著的差异 $(p<0.001)$, 但群落I的落叶物种多度显 著小于常绿物种, 而群落III呈现相反的趋势(图 3B)。其他 3 个群落类型中常绿与落叶物种的多度差
异不显著 $(p>0.05)$ 。

群落II、群落III和群落 V中落叶物种的胸高断面 积均显著 $(p<0.001)$ 大于常绿物种(图3C)。群落 $\mathrm{I}$ 与 群落IV的常绿和落叶物种的胸高断面积差异不显 著 $(p>0.05)$, 但群落IV中落叶物种的胸高断面积略 高于常绿树种。

群落II、群落III和群落V中落叶物种的重要值显 著大于常绿物种 $(p<0.01)$ (图3D), 群落I中的常绿 物种重要值显著大于落叶物种, 群落IV的常绿物种 重要值大于落叶物种, 但差异并不显著 $(p>0.05)$ 。

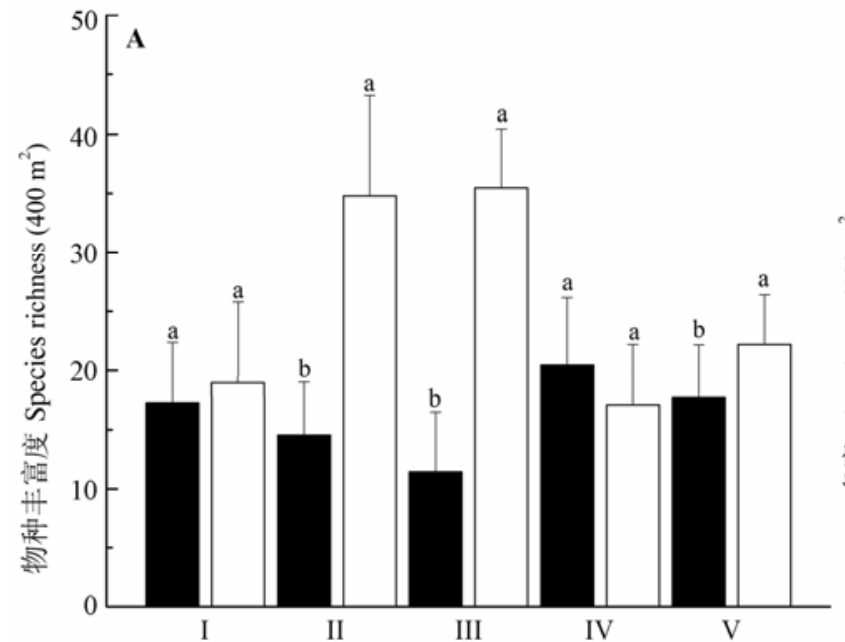

群落类型 Community type

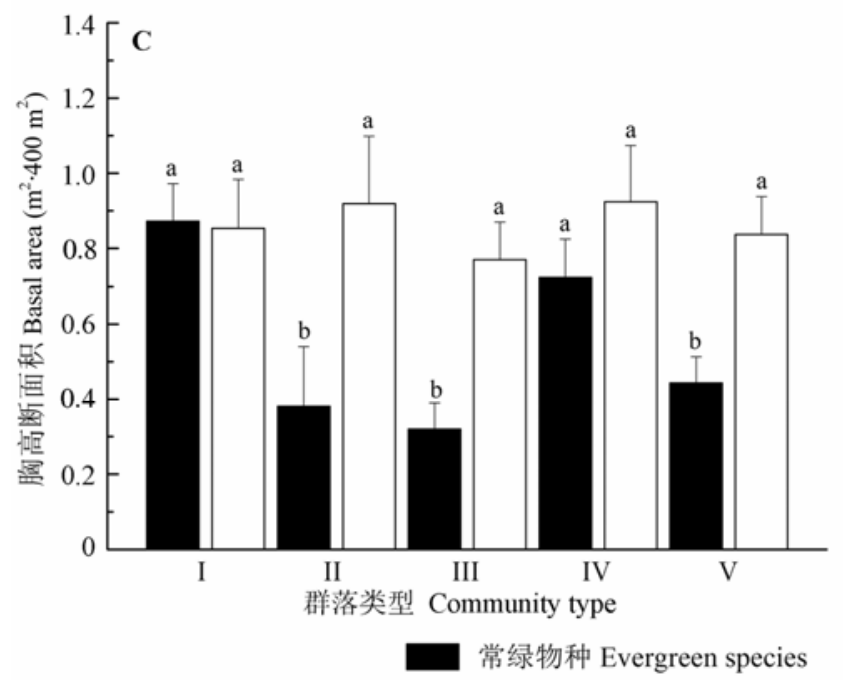

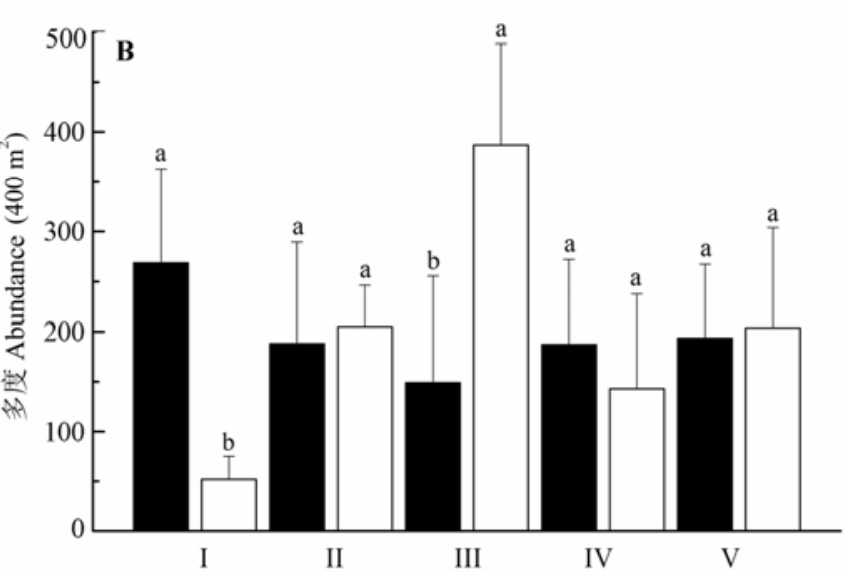

群落类型 Community type

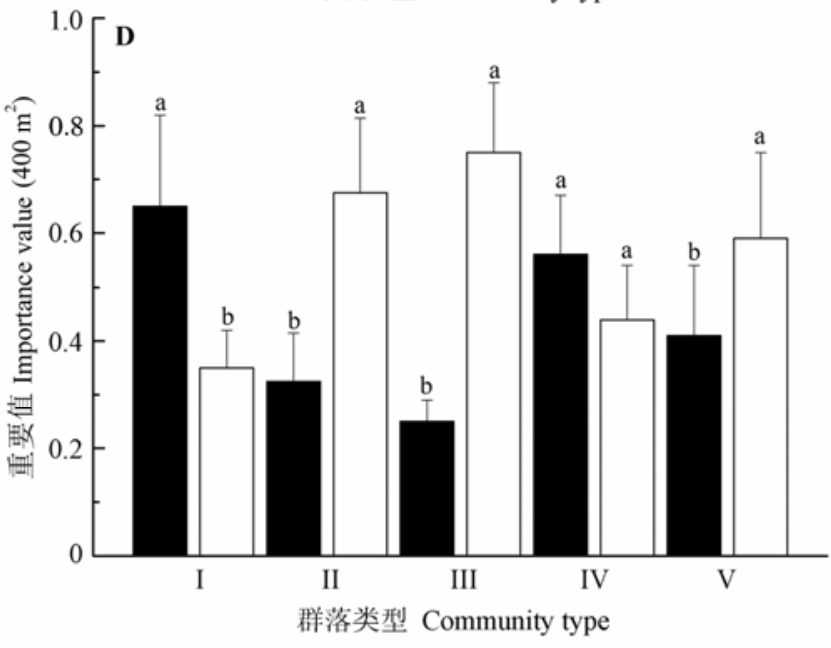

落叶物种 Deciduous species

图3 鄂西南两个保护区亚热带常绿落叶阔叶混交林5种群落类型的常绿和落叶物种丰富度、多度、胸高断面积和重要值(平 均值土标准偏差)。不同小写字母(a, b)表示显著差异 $(p<0.05)$ I、II、III、IV、V分别为青冈-翅柃+尖连荵茶群落, 川陕鹅耳 枥+青冈-翅柃群落, 川陕鹅耳枥+青冈-水马桑群落, 光叶水青冈+多脉青冈-翅柃群落和川陕鹅耳枥+交让木+包果柯-翅柃 群落。

Fig. 3 Species richness, abundance, basal area and importance value of the five forest types in the subtropical evergreen-deciduous broadleaved mixed forest across two nature reserves in Southwest Hubei, China (mean $\pm S D$ ). Different lowercase letters (a, b) indicate significant differences at the level of 0.05 . I, II, III, IV, V indicate different community types: Cyclobalanopsis glauca-Eurya alata + Camellia cuspidata, Carpinus fargesiana + Cyclobalanopsis glauca-Eurya alata, Carpinus fargesiana + Cyclobalanopsis glauca-Weigela japonica, Fagus lucida + Cyclobalanopsis multinervis-Eurya alata, Carpinus fargesiana + Daphniphyllum macropodum + Lithocarpus cleistocarpus-Eurya alata. 
3.3 不同径级的常绿和落叶物种丰富度、多度、胸 高断面积及重要值比例的变化

除群落I外, 所有群落类型内的常绿和落叶物 种丰富度比例均随胸径级的增加而下降(图4A)。除 群落IV内 $1-5 \mathrm{~cm}$ 的径级外, 其他群落类型各径级中 的落叶物种丰富度均大于常绿物种。

除群落I外, 常绿和落叶物种多度在群落内所 占的比例随径级的增加而逐渐下降(图4B)。除群落 III外, 各群落内 1-5 cm 径级的常绿物种多度均大于 落叶物种, 在5-10 $\mathrm{cm}$ 的径级内, 群落I和群落IV的 常绿物种多度大于落叶物种, 群落II、群落III和群落 $\mathrm{V}$ 的落叶物种多度大于常绿物种。除群落I外, 各群 落的落叶物种多度在 $\geqslant 10 \mathrm{~cm}$ 的径级内均大于常绿 物种。

各群落类型内常绿物种和落叶物种的胸高断面
积比例均随着径级的增加而升高(图4C)。群落II、群 落III和群落 $\mathrm{V}$ 中落叶物种的胸高断面积比例在 $1-5$ $\mathrm{cm}$ 和5-10 $\mathrm{cm}$ 的径级内大于常绿物种, 群落I和群落 IV中则呈现相反的趋势。各群落胸径 $\geqslant 10 \mathrm{~cm}$ 的落 叶物种比例均大于常绿物种。

除群落III外, 常绿物种的重要值在1-5 cm径级 内均大于落叶物种(图4D)。在5-10 cm的径级内, 群 落I和群落IV的常绿物种重要值大于落叶物种, 群 落II、群落III和群落 V的落叶物种重要值大于常绿物 种。各群落胸径 $\geqslant 10 \mathrm{~cm}$ 的落叶物种重要值均大于 常绿物种。

\section{4 群落物种组成与环境因子的关系}

基于距离矩阵的多元回归分析(MRM)结果表 明: 环境因子可以解释物种组成变化的 $59 \%$, 海拔、 坡度、坡向、土壤全氮、土壤全磷、土壤碱解氮、
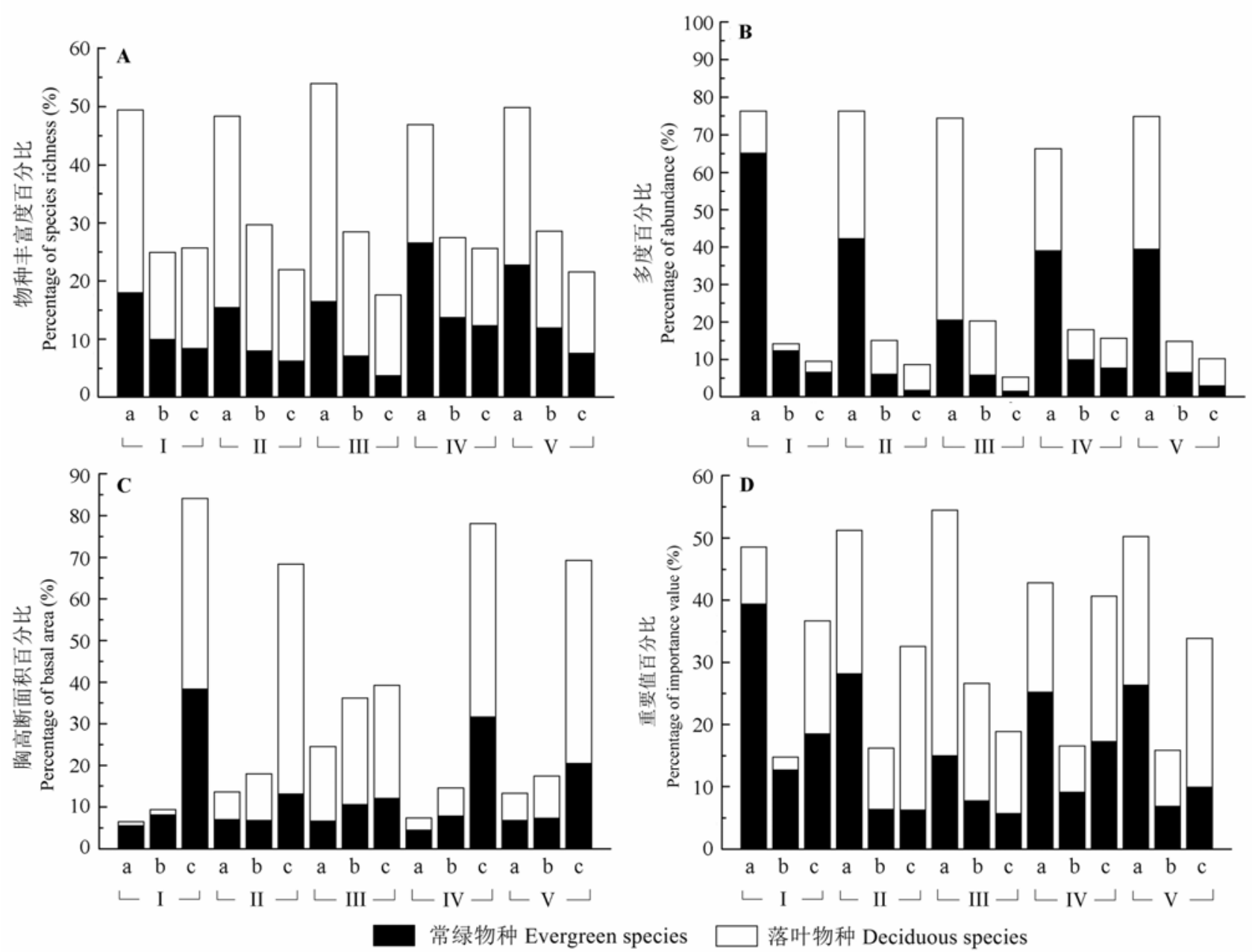

图4 鄂西南两个保护区亚热带常绿落叶阔叶混交林5种群落类型的常绿和落叶物种不同径级的物种丰富度、多度、胸高断面 积和重要值比例。a, 胸径 $1-5 \mathrm{~cm} ; \mathrm{b}$, 胸径 $5-10 \mathrm{~cm}$; c, 胸径 $\geqslant 10 \mathrm{~cm}$ 。I-V同图3。

Fig. 4 Evergreen/deciduous ratio of species richness, abundance, basal area and importance value with size class in subtropical evergreen-deciduous broadleaved mixed forest across two nature reserves in Southwest Hubei, China. a, DBH 1-5 cm; b, DBH 5-10 $\mathrm{cm} ; \mathrm{c}, D B H \geqslant 10 \mathrm{~cm} ; D B H$, diameter at breast height. I-V see Fig. 3. 
表2＼cjkstart鄂西南两个保护区亚热带常绿落叶阔叶混交林内环境因子对物种 分布的影响

Table 2 Effects of environmental factors on species distribution in subtropical evergreen-deciduous broadleaved mixed forest across two nature reserves in Southwest Hubei, China

\begin{tabular}{lll}
\hline 环境因子 & $R^{2}$ & $p$ \\
Environmental variables & & \\
\hline 海拔 Elevation & 0.1267 & $0.001^{* * *}$ \\
坡度 Slope & 0.0285 & $0.001^{* * *}$ \\
坡向 Aspect & 0.0024 & $0.014^{* *}$ \\
土壤含水量 Soil water content & 0.0017 & 0.071 \\
$\mathrm{pH}$ & 0.0029 & 0.059 \\
土壤有机质 Soil organic matter & 0.0007 & 0.092 \\
土壤全氮 Total nitrogen & 0.0011 & $0.002^{* * *}$ \\
土壤全磷 Total phosphorus & 0.0364 & $0.001^{* * *}$ \\
土壤碱解氮 Available nitrogen & 0.0178 & $0.001^{* * *}$ \\
土壤速效磷 Available phosphorus & 0.2457 & $0.001^{* * *}$ \\
\hline
\end{tabular}

*, 在 0.05 水平上显著相关; $* *$, 在 0.01 水平上显著相关; $* * *$, 在 0.001 水 平上显著相关; $R^{2}$, 决定系数。

*, difference is significant at 0.05 level; $* *$, difference is significant at 0.01 level; ***, difference is significant at 0.001 level; $R^{2}$, coefficient of determination.

土壤速效磷是影响研究区群落分布的主要因子 (表2)。

整体来看, 群落I主要分布在坡度大、全磷、全 氮含量高、海拔在1 $538 \mathrm{~m}$ 左右的阴坡; 群落II主要 分布在坡度较大、速效磷含量低、海拔在 $1470 \mathrm{~m}$ 左 右的阴坡和半阴坡; 群落III主要分布在坡度较小, 全磷含量较高、海拔在1 $762 \mathrm{~m}$ 左右的阳坡和半阳 坡; 群落IV主要分布在碱解氮和全氮含量高、海拔 在1 $587 \mathrm{~m}$ 左右的阴坡和半阴坡; 群落 $\mathrm{V}$ 主要分布在
坡度小、速效磷含量高、全磷和碱解氮含量低、海 拔在1 $406 \mathrm{~m}$ 左右的半阴坡。

采用多元逐步回归分析对各群落常绿和落叶物 种丰富度与环境因子关系的研究(表3)表明, 除土壤 含水量和有机质之外, 其他环境因子在不同群落类 型间与常绿和落叶物种呈现显著的相关性 $(p<$ 0.05)。海拔高度与群落III和群落 V的落叶物种显著 相关。坡度与群落I和群落IV的落叶物种显著负相 关。坡位与群落I、群落III和群落IV显著相关。土壤 氮与群落I、群落II、群落III和群落IV显著相关。土 壤磷与群落II和群落 $\mathrm{V}$ 显著负相关。

\section{4 讨论}

\section{1 亚热带常绿落叶阔叶混交林群落的数量分类 与排序}

通过TWINSPAN及DCA方法对鄂西南木林子 自然保护区和星斗山自然保护区的亚热带常绿落叶 阔叶混交林进行数量分类和排序, 将两个保护区的 92 个样地分成了 5 个群落类型。TWINSPAN划分出 的群落类型在DCA排序图上能明显地区分开, 说明 排序与分类结果基本吻合, 数量化的分类结果是可 信的。

植被分类是植被生态学研究中最复杂的一个问 题，直到现在还没有植被学家们认同的统一分类原 则和分类系统(宋永昌, 2004)。而我国亚热带地区植

表3 鄂西南两个保护区亚热带常绿落叶阔叶混交林5种群落常绿和落叶物种丰富度与环境因子的多元逐步回归分析

Table 3 Multiple regression analysis between species richness and environmental variables in the five forest types in subtropical evergreen-deciduous broadleaved mixed forest across two nature reserves in Southwest Hubei, China

\begin{tabular}{|c|c|c|c|c|c|c|c|c|c|c|c|c|c|}
\hline \multirow{2}{*}{$\begin{array}{l}\text { 类型1) } \\
\text { Type }^{1)}\end{array}$} & \multirow{2}{*}{$\begin{array}{l}\text { 物种丰富度 }^{2)} \\
\text { Species } \\
\text { richness }^{2)}\end{array}$} & \multicolumn{10}{|c|}{ 环境变量 ${ }^{3)}$ Environmental variables ${ }^{3)}$} & \multicolumn{2}{|c|}{ 参数 ${ }^{4)}$ Parameter $^{4)}$} \\
\hline & & $E$ & $S$ & A & SWC & $\mathrm{pH}$ & SOM & $\mathrm{TN}$ & $\mathrm{TP}$ & AN & AP & AIC & $p$ \\
\hline \multirow[t]{2}{*}{ I } & ESR & & & -0.26 & & -1.16 & & 1.11 & & & & -46.83 & $0.020 *$ \\
\hline & DSR & & -1.55 & & & & & & & & & -32.35 & 0.329 \\
\hline \multirow[t]{2}{*}{ II } & ESR & & & & & & & 1.26 & -4.31 & 2.54 & -0.95 & -55.14 & $0.008^{*}$ \\
\hline & DSR & & & & & & & & & & & -55.29 & $0.007^{*}$ \\
\hline \multirow[t]{2}{*}{ III } & ESR & & & & & & & & & & & -41.90 & $0.019 *$ \\
\hline & DSR & 7.85 & & 0.29 & & & & & & -0.68 & & -64.30 & $0.032 *$ \\
\hline \multirow[t]{2}{*}{ IV } & ESR & & & -0.13 & & & & 4.16 & & 1.96 & & -11.01 & $0.021^{*}$ \\
\hline & DSR & & -1.98 & & & & & & & & & -24.49 & 0.053 \\
\hline \multirow[t]{2}{*}{ V } & ESR & & & & & & & & -0.67 & & -0.57 & -107.40 & $0.022 *$ \\
\hline & DSR & -2.32 & & & & & & & & & & -129.68 & $0.005^{*}$ \\
\hline
\end{tabular}

1) I-V同图3。2) DSR，落叶物种丰富度; ESR，常绿物种丰富度。3) A，坡向; AN，土壤碱解氮; AP，土壤速效磷; E，海拔; pH，土壤 $\mathrm{pH}$ 值; S, 坡度; SOM， 土壤有机质; SWC, 土壤含水量; TN, 土壤全氮; TP, 土壤全磷。4) AIC, 赤池信息准则。*, 显著相关 $(p<0.05)$ 。

1) I-V see Fig. 3. 2) DSR, deciduous species richness; ESR, evergreen species richness; 3) A, aspect; AN, available nitrogen of soil; AP, available phosphorus of soil; E, elevation; $\mathrm{pH}$, pH value of soil; S, slope; SOM, soil organic matter; SWC, soil water content; TN, total nitrogen of soil; TP, total phosphorus of soil. 4) AIC, Alkaike information criterion. *, statistical is significant at 0.05 level. 
被具有复杂多样、次生性强和过渡类型多等特点, 更增加了该地区植被分类的困难(赖江山等, 2010)。 传统的植物群落分类多根据群落的外貌特征及群落 的种类组成划分群落类型, 个人经验对分类结果的 影响比较大(刘海江和郭柯, 2003; 刘万德等, 2010)。 随着植被研究的精度要求不断提高, 提供客观归类 和划分结果的数量分类方法在植被分类中越来越重 要(袁秀等, 2013)。目前数量生态学中的分类和排序 方法已成为现代植被生态学研究中必不可少的手 段, 双向指示种分析法(TWINSPAN)和除趋势对应 分析法(DCA) 已广泛应用于森林和草地等植物群落 分析(Ozinga et al., 2005; 孙菊等, 2009; 廉凯敏等, 2015)。本研究也证实了TWINSPAN分类与DCA排 序这两种方法相结合应用于亚热带常绿落叶阔叶混 交林植被数量分析是可行的, 而且可以相互补充和 交叉检验。

\section{2 常绿和落叶物种比例随群落类型的变化及其 环境解释}

由于叶片是植物光合作用的主要场所, 因而叶 片的物候过程对于群落外貌、林下环境、调落物分 解和生态系统生产力具有重要作用(Bohlman et al., 1998; Quigley \& Platt, 2003)。落叶是物种适应环境 胁迫的一种重要策略, 通过落叶可以回避不利生境 对树木生长造成的伤害和不利影响 (Poorter \& Markesteijn, 2008), 低温和水分胁迫是阔叶树种落 叶的重要原因(Lechowicz, 1984; Reich et al., 2004)。 与热带部分地区树种因土壤水分亏缺而出现旱季落 叶的情况不同(Williams et al., 2008; de Faria Lopes et al., 2012), 亚热带常绿落叶阔叶混交林的形成更 多受到海拔升高而形成的低温胁迫的影响(OliveiraFilho et al., 2006; 白坤栋等, 2010; 宋坤, 2012)。回 归分析中土壤含水量与常绿和落叶物种分布并无显 著的相关性, 这个结果证明了研究区常绿和落叶物 种的变化与土壤水分无关。温度是限制植物组成、 生长、繁殖和分布的重要因子(Woodward, 1987)。 研究地区冬季气温较低, 一些喜温且生长迅速竞争 能力强的常绿阔叶树种受到限制, 但绝对低温尚较 高, 因此较耐寒的常绿阔叶树与落叶阔叶树均能生 长, 最终在该地段形成了亚热带常绿落叶阔叶混交 林(吴征镒, 1980)。

从物种组成和群落结构来看, 研究区各群落类 型常绿和落叶物种存在一定的差异。群落I和群落IV
的常绿和落叶物种在群落内的差异多不显著或者常 绿物种大于落叶物种, 而群落II、群落III和群落 V则 表现为落叶物种大于常绿物种。造成这种差异的主 要原因可能是环境差异和人为干扰。环境是影响物 种组成的决定性因素, 环境因子组成的变化产生了 不同的生境, 从而引起不同地带及区域的物种差异 (Toledo et al., 2011)。而人为干扰能够显著地改变群 落结构和物种组成, 从而影响群落的发展方向 (Lomolino, 2001; Haberl et al., 2007; Nogués-Bravo et al., 2008)。群落III位于海拔较高的阳坡, 随着海 拔的升高, 气温逐渐降低, 光照强度增加, 较低的 气温和阳坡较好的光照条件促进落叶物种的生长 (Malhi et al., 2010)。充足的光照也促进土壤种子库 萌发, 使群落内幼苗和幼树的密度较大。同时, 群落 III位于保护区森林防火隔离带附近, 较频繁地受到 了人为的干扰, 干扰提高了林下的光照条件, 导致 群落内喜光的落叶树种增加和耐阴的常绿树种减少 (Hawthorne, 1996; Bongers et al., 2009)。群落II和群 落 $\mathrm{V}$ 分布于低海拔地区，长期受到人类樵采等活动 的影响, 林下的光照条件较好, 群落内的落叶物种 大于常绿物种。群落I和群落IV主要位于阴坡, 且人 为干扰较少, 林内光照条件较差, 适宜常绿物种的 生长。

除地形因子和人为干扰之外, 土壤养分也对常 绿和落叶物种比例的变化产生了一定的影响。落叶 物种分布区的土壤氮含量常被认为高于常绿物种分 布区, 其原因是落叶物种比常绿物种具有更高的氮 矿化速率(Aerts \& Chapin, 1999; Cornwell et al., 2008), 然而也有研究表明常绿和落叶物种的氮矿 化速率并无显著差异(Reich et al., 2001; Booth et al., 2005)。本研究发现土壤氮含量在多数群落内与常绿 物种丰富度显著正相关, 这可能与不同群落类型的 物种属性及真菌差异有关(Mueller et al., 2012)。总 体来看, 研究区常绿物种更易受土壤养分的影响。 关于土壤养分对各群落内常绿和落叶物种分布的影 响有待进一步深入分析。

\section{3 常绿和落叶物种比例随胸径级的变化}

除群落III外, 各群落类型小径级 $(1-5 \mathrm{~cm})$ 内落 叶物种的物种丰富度高于常绿物种, 但多度、胸高 断面积和重要值却表现为落叶物种小于常绿物种, 这主要与常绿和落叶物种的生活型属性有关。研究 区群落内小径级个体的生活型主要是小乔木和灌 
木, 而大乔木个体密度相对较低。这些小乔木和灌 木物种以常绿树种为主, 因此出现了小径级内落叶 物种丰富度高但多度、胸高断面积和重要值低的现 象。较高强度的干扰能够提高落叶树种在群落中的 比例(丁易和藏润国, 2008), 群落III的小径级在各个 指标上都是落叶树种占优势, 这可能说明人为干扰 和环境条件显著影响了该群落的更新和发展方向, 导致该群落在未来一段时间内都将以落叶物种为 主。大径级 $(\geqslant 10 \mathrm{~cm})$ 的落叶物种在多数群落内的物 种丰富度、多度、胸高断面积和重要值均大于常绿 物种, 表明落叶树种在林冠层占据显著的优势, Chabot和Hicks (1982)的研究也发现, 光照条件较好 的林冠层落叶物种更多。林冠层落叶树种占据优势 能够显著影响林下光照条件, 从而影响森林更新和 物种多样性(Quigley \& Platt, 2003)。落叶物种具有更 高的资源养分利用效率(Kloeppel et al., 2000), 能够 利用夏季良好的水热条件迅速获得碳水化合物完成 高生长, 在与常绿树种的竞争过程中居于优势地位 (Antúnez et al., 2001)。同时, 落叶物种采取了落叶 的策略来适应研究区的冬季低温胁迫, 而常绿物种 则保留叶片越冬, 低温可能损害常绿树种的气孔和 光合速率而使常绿植物生长受到严重制约(Wyka \& Oleksyn, 2014), 且较大的季节性温差所引起的冰凌 和雪灾也可能造成常绿植物受到伤害从而限制其在 林冠层的优势(白坤栋等, 2010)。林下的常绿树木由 于林冠层的郁闭而受到光强的限制。尽管在林冠层 落叶期间(晚秋到早春), 林下光照条件可以由于林 冠层的落叶而得到改善, 但低温限制了林下常绿树 木的生长。这种竞争最终形成了林冠层以落叶阔叶 树为主和林下层以常绿树种为主的格局。

有关常绿、落叶物种随群落类型变化的具体机 制还需要进一步深入细致研究, 如群落所处的具体 小生境(土壤、地形和小气候等因子)、不同物种的 生理生态特性与生态适应性等方面。这些研究将随 着鄂西南地区森林动态样地监测平台的建设逐步开 展。通过长期定位观测和基础研究, 阐明该地区常 绿落叶阔叶混交林的恢复动态规律, 可为该地区基 于生态系统功能的恢复实践提供重要的理论依据。

基金项目 楚天学者计划项目及湖北省重点(特色) 学科(2013XKJS_10517)和湖北省教育厅重点项目 (D20122901)。

致谢 感谢湖北民族学院林学园艺学院2012级本科
生、硕士生冯广、刘峻城、林勇及木林子国家级自 然保护区米显齐书记等人在野外调查工作中给予的 帮助。

\section{参考文献}

Aerts R, Chapin FS III (1999). The mineral nutrition of wild plants revisited: A re-evaluation of processes and patterns. Advances in Ecological Research, 30, 1-67.

Ai XR, Tan XJ (1999). On the population structure of Davidia involucrata in Xingdoushan protected region. Journal of Hubei Institute for Nationalities (Natural Sciences), 17, 12-15. (in Chinese with English abstract) [艾训儒, 谭建 锡 (1999). 星斗山自然保护区珙桐种群结构特征研究. 湖北民族学院学报(自然科学版), 17, 12-15.]

An SQ, Zhang JH, Tan JK, Zhu XL, Zhao RL (1998). Review of studies on secondary forests in north subtropics, China. Journal of Wuhan Botanical Research, 16, 268-272. (in Chinese with English abstract) [安树青, 张久海, 谈健康, 朱学雷, 赵儒林 (1998). 中国北亚热带次生森林植被研 究述评. 武汉植物学研究, 16, 268-272.]

Antúnez I, Retamosa EC, Villar R (2001). Relative growth rate in phylogenetically related deciduous and evergreen woody species. Oecologia, 128, 172-180.

Bai KD, Jiang DB, Cao KF, Wan XC, Liao DB (2010). Photosynthetic response to seasonal temperature changes in evergreen and deciduous broad-leaved trees in montane forests of Ailao Mountain and Mao'er Mountain. Acta Ecologica Sinica, 30, 905-913. (in Chinese with English abstract) [白坤栋, 蒋得斌, 曹坤芳, 万贤崇, 廖德宝 (2010). 哀牢山和猫儿山中山常绿和落叶阔叶树光合特 性对季节温度变化的响应. 生态学报, 30, 905-913.]

Ban JD, Qi GS (1995). A Study of Vegetation of Western Hubei. Press of Huazhong University of Science and Technology, Wuhan. (in Chinese) [班继德, 漆根深 (1995). 鄂西植被 研究. 华中理工大学出版社, 武汉.]

Bohlman SA, Adams JB, Smith MO, Peterson DL (1998). Seasonal foliage changes in the Eastern Amazon Basin detected from landsat thematic mapper satellite images. Biotropica, 30, 376-391.

Bongers F, Poorter L, Hawthorne WD, Sheil D (2009). The intermediate disturbance hypothesis applies to tropical forests, but disturbance contributes little to tree diversity. Ecology Letters, 12, 798-805.

Booth MS, Stark JM, Rastetter E (2005). Controls on nitrogen cycling in terrestrial ecosystems: A synthetic analysis of literature data. Ecological Monographs, 75, 139-157.

Cao TR, Qi CJ, Yu XL (1997). Studies on species diversity of Fagus lucida communities on the Badagongshan Mountain, Hunan. Chinese Biodiversity, 5(2), 112-120. (in Chinese with English abstract) [曹铁如, 祁承经, 喻勋林 (1997). 湖南八大公山亮叶水青冈群落物种多样性的研 
究. 生物多样性, 5(2), 112-120.]

Chabot BF, Hicks DJ (1982). The ecology of leaf life spans. Annual Review of Ecology and Systematics, 13, 229-259.

Condit R (1998). Tropical Forest Census Plots: Methods and Results from Barro Colorado Island, Panama and a Comparison with Other Plots. Springer Science \& Business Media, Berlin.

Cornwell WK, Cornelissen JHC, Amatangelo K, Dorrepaal E, Eviner VT, Godoy O, Hobbie SE, Hoorens B, Kurokawa H, Pérez-Harguindeguy N, Quested HM, Santiago LS, Wardle DA, Wright IJ, Aerts R, Allison SD, van Bodegom P, Brovkin V, Chatain A, Callaghan TV, Díaz S, Garnier E, Gurvich DE, Kazakou E, Klein JA, Read J, Reich PB, Soudzilovskaia NA, Vaieretti MV, Westoby M (2008). Plant species traits are the predominant control on litter decomposition rates within biomes worldwide. Ecology Letters, 11, 1065-1071.

de Faria Lopes S, Schiavini I, do Vale VS, do Prado Júnior JA, de Silvério Arantes C (2012). Historical review of studies in seasonal semideciduous forests in Brazil: A perspective for conservation. Brazilian Geographical Journal: Geosciences and Humanities Research Medium, 3, 21-40.

Ding Y, Zang RG (2008). Changes in deciduous trees during recovery of tropical lowland rain forests on abandoned shifting cultivation lands in Hainan Island, South China. Biodiversity Science, 16, 103-109. (in Chinese with English abstract) [丁易, 藏润国 (2008). 海南岛热带低地雨 林刀耕火种弃耕地恢复过程中落叶树种的变化. 生物 多样性, 16, 103-109.]

Fang JY (2001). Re-discussion about the forest vegetation zonation in eastern China. Acta Botanica Sinica, 43, 522-533. (in Chinese with English abstract) [方精云 (2001). 也论我国东部植被带的划分. 植物学报，43, 522-533.]

Fang YP, Liu SX (2006). Research on the national protected plants in Xingdoushan Nature Reserve in Hubei Province. Subtropical Plant Science, 34(3), 48-52. (in Chinese with English abstract) [方元平, 刘胜祥 (2006). 湖北星斗山 自然保护区国家重点保护野生植物调查研究. 亚热带 植物科学, 34(3), 48-52.]

Fu SX (2002). Flora of Hubeiensis. Hubei Science and Technology Press, Wuhan. (in Chinese) [傅书遐 (2002). 湖北 植物志. 湖北科学技术出版社, 武汉.]

Ge JW, Hu HX, Li B (2009). Scientific Survey and Study on Forest Biodiversity in Mulinzi Nature Reserve of Hubei, Central China. Science Press, Beijing. (in Chinese) [葛继 稳, 胡鸿兴, 李博 (2009). 湖北木林子自然保护区森林 生物多样性研究. 科学出版社, 北京.]

Haberl H, Erb KH, Krausmann F, Gaube V, Bondeau A, Plutzar C, Gingrich S, Lucht W, Fischer-Kowalski M (2007). Quantifying and mapping the human appropriation of net primary production in earth's terrestrial ecosystems. Proceedings of the National Academy of Sciences of the United States of America, 104, 12942-12947.

Han WH, Li XK, Ye D, Lü SH, Xiang WS, Song TQ, Cao HL (2009). Interspecific association and correlation between dominant woody plant species in an evergreen and deciduous broad-leaved mixed forest of karst area, Northwest Guangxi. Journal of Mountain Science, 27, 719-726. (in Chinese with English abstract) [韩文衡, 李先琨, 叶 铎, 吕仕洪, 向悟生, 宋同清, 曹洪麟 (2009). 桂西北 喀斯特区常绿落叶阔叶混交林种群种间联结性与相关 性. 山地学报, 27, 719-726.]

Hawthorne WD (1996). Holes and the sums of parts in Ghanaian forest: Regeneration, scale and sustainable use. Proceedings of the Royal Society of Edinburgh. Section B. Biological Sciences, 104, 75-176.

Kloeppel BD, Gower ST, Vogel JG, Reich PB (2000). Leaflevel resource use for evergreen and deciduous conifers along a resource availability gradient. Functional Ecology, 14, 281-292.

Lai JS, Mi XC, Ren HB, Ma KP (2010). Numerical classification of associations in subtropical evergreen broad-leaved forest based on multivariate regression trees-a case study of $24 \mathrm{hm}^{2}$ Gutianshan forest plot in China. Chinese Journal of Plant Ecology, 34, 761-769. (in Chinese with English abstract) [赖江山, 米湘成, 任海保, 马克平 (2010). 基于多元回归树的常绿阔叶林群丛数量分类一以古田 山24公顷森林样地为例. 植物生态学报, 34, 761-769.]

Lechowicz MJ (1984). Why do temperate deciduous trees leaf out at different times? Adaptation and ecology of forest communities. The American Naturalist, 124, 821-842.

Lian KM, Wu YJ, Zhang L, Zhao LL, Zhang F (2015). Numerical classification and ordination of wild Castanea mollissima communities in Taikuan River Nature Reserve, Shanxi. Chinese Journal of Ecology, 34, 33-39. (in Chinese with English abstract) [廉凯敏, 吴应建, 张丽, 赵璐 璐, 张峰 (2015). 太宽河自然保护区板栗群落数量分类 与排序. 生态学杂志, 34, 33-39.]

Lichstein JW (2007). Multiple regression on distance matrices: A multivariate spatial analysis tool. Plant Ecology, 188, 117-131.

Liu HB, Wang QG, Lu JM, Xu YZ, Lu ZJ, Qiao XJ, Bao DC, Guo YL, Meng HJ, Jiang MX (2014). Root-sprouting ability in an evergreen and deciduous broad-leaved mixed forest. Chinese Science Bulletin, 59, 3491-3498. (in Chinese) [刘海波, 王庆刚, 路俊盟, 徐耀粘, 卢志军, 乔秀 娟, 鲍大川, 郭屹立, 孟红杰, 江明喜 (2014). 八大公 山常绿落叶阔叶混交林根萌能力. 科学通报, 59, 3491-3498.]

Liu HJ, Guo K (2003). Classification and ordination analysis of plant communities in inter-dune lowland in Hunshandak 
Sandy Land. Acta Ecologica Sinica, 23, 2163-2169. (in Chinese with English abstract) [刘海江, 郭柯 (2003). 浑 善达克沙地丘间低地植物群落的分类与排序. 生态学 报, 23, 2163-2169.]

Liu WD, Ding Y, Zang RG, Su JR, Yang M, Cai DL, Li RC, Chen SW (2010). Quantitative classification and ordination of low-altitudinal tropical forests in Bawangling, Hainan Island. Chinese Journal of Ecology, 29, 15261532. (in Chinese with English abstract) [刘万德, 丁易, 蔵润国, 苏建荣, 杨民, 蔡笃否, 李儒财, 陈少伟 (2010). 海南岛霸王岭林区低海拔热带林群落数量分类 与排序. 生态学杂志, 29, 1526-1532.]

Lomolino MV (2001). Elevation gradients of species-density: Historical and prospective views. Global Ecology and Biogeography, 10, 3-13.

Lu SF, Liu SX, Fang YP (2005). A preliminary research of invasive species around Xingdoushan National Nature Reserve, Hubei. Journal of Huanggang Normal University, 25(3), 48-52. (in Chinese with English abstract) [卢 少飞, 刘胜祥, 方元平 (2005). 星斗山国家级自然保护 区外来入侵植物初步研究. 黄冈师范学院学报, 25(3), 48-52.]

Malhi Y, Silman M, Salinas N, Bush M, Meir P, Saatchi S (2010). Introduction: Elevation gradients in the tropics: Laboratories for ecosystem ecology and global change research. Global Change Biology, 16, 3171-3175.

Mueller KE, Hobbie SE, Oleksyn J, Reich PB, Eissenstat DM (2012). Do evergreen and deciduous trees have different effects on net $\mathrm{N}$ mineralization in soil. Ecology, 93, 1463-1472.

Nogués-Bravo D, Araújo MB, Romdal T, Rahbek C (2008). Scale effects and human impact on the elevational species richness gradients. Nature, 453, 216-219.

Oliveira-Filho AT, Jarenkow JA, Rodal MJN (2006). Floristic relationships of seasonally dry forests of eastern South America based on tree species distribution patterns. In: Pennington RT, Ratter JA eds. Neotropical Savannas and Seasonally Dry Forests: Plant Diversity, Biogeography, and Conservation. CRC Press, Boca Raton, USA. 151184.

Ozinga WA, Schaminée JHJ, Bekker RM, Bonn S, Poschlod P, Tackenberg O, Bakker J, van Groenendael JM (2005). Predictability of plant species composition from environmental conditions is constrained by dispersal limitation. Oikos, 108, 555-561.

Poorter L, Markesteijn L (2008). Seedling traits determine drought tolerance of tropical tree species. Biotropica, 40, 321-331.

Quigley MF, Platt WJ (2003). Composition and structure of seasonally deciduous forests in the Americas. Ecological Monographs, 73, 87-106.

Reich PB, Bakken P, Carlson D, Frelich LE, Friedman SK,
Grigal DF (2001). Influence of logging, fire, and forest type on biodiversity and productivity in southern boreal forests. Ecology, 82, 2731-2748.

Reich PB, Uhl C, Walters MB, Prugh L, Ellsworth DS (2004). Leaf demography and phenology in Amazonian rain forest: A census of 40000 leaves of 23 tree species. Ecological Monographs, 74, 3-23.

Shen ZH, Zhao ZE, Wu JQ, Jin YX, Huang HD, Jiang MX (1999). Spatial pattern and relation with the topographical factors of the rare pare species at Dalaoling in the Three Gorges Region. Acta Phytoecologica Sinica, 23, 171-180. (in Chinese with English abstract) [沈泽吴，赵子恩，吴金 清, 金义兴, 黄汉东, 江明喜 (1999). 三峡地区大老岭 珍稀植物的分布格局及其与地形因子的关系. 植物生 态学报, 23, 171-180.]

Shen ZH, Fang JY (2001). Niche comparison of two Fagus species based on the topographic patterns of their populations. Acta Phytoecologica Sinica, 25, 392-398. (in Chinese with English abstract) [沈泽昊, 方精云 (2001). 基 于种群分布地形格局的两种水青冈生态位比较研究. 植物生态学报, 25, 392-398.]

Song K (2012). Vegetation Characteristic of Evergreendeciduous Broadleaved Forest Ecotone and Its Formation Mechanism, a Study in Anhui. PhD dissertation, East China Normal University, Shanghai. 50-60. (in Chinese with English abstract). [宋坤 (2012). 安徽常绿阔叶林落叶阔叶林交错带的森林植被特征及其成因. 博士学 位论文, 华东师范大学, 上海. 50-60.]

Song YC (1999). Perspective of the vegetation zonation of forest region in eastern China. Acta Botanica Sinica, 41, 541-552. (in Chinese with English abstract) [宋永昌 (1999). 中国东部森林植被带划分之我见. 植物学报, 41, 541-552.]

Song YC (2004). Tentative classification scheme of evergreen broad-leaved forests of China. Acta Phytoecologica Sinica, 28, 435-448. (in Chinese with English abstract) [宋永昌 (2004). 中国常绿阔叶林分类试行方案. 植物生态学报, 28, 435-448.]

Sun J, Li XZ, Hu YM, Wang XW, Lü JJ, Li ZM, Chen HW (2009). Classification, species diversity, and species distribution gradient of permafrost wetland plant communities in Great Xing'an Mountains valleys of Northeast China. Chinese Journal of Applied Ecology, 20, 2049-2056. (in Chinese with English abstract) [孙菊, 李 秀珍, 胡远满, 王宪伟, 吕久俊, 李宗梅, 陈宏伟 (2009). 大兴安岭沟谷冻土湿地植物群落分类、物种多 样性和物种分布梯度. 应用生态学报, 20, 2049-2056.]

Tang JM, Dai HH, Xun JG, Zhai MP (2010). Effects on regeneration pattern for woodland fertility of mixed evergreen and deciduous broadleaved mountain forests. Hubei Forestry Science and Technology, (6), 7-10. (in Chinese with 
English abstract) [汤景明, 戴汉会, 荀继刚, 翟明普 (2010). 山地常绿落叶阔叶混交林更新方式对林地肥力 的影响. 湖北林业科技, (6), 7-10.]

Toledo M, Poorter L, Peña-Claros M, Alarcón A, Balcázar J, Leaño C, Licona JC, Bongers F (2011). Climate and soil drive forest structure in Bolivian lowland forests. Journal of Tropical Ecology, 27, 333-345.

Wang ZX, Lei Y, Fujiwara K, Liu LH, Xue YG (2006). Community classification, species composition, and regeneration of Fagus lucida forests in subtropical mountains, China. Biodiversity Science, 14, 29-40. (in Chinese with English abstract) [汪正祥, 雷耘, Fujiwara K, 刘林翰, 薛 跃规 (2006). 亚热带山地亮叶水青冈林的群落分类及 物种组成与更新. 生物多样性, 14, 29-40.]

Williams LJ, Bunyavejchewin S, Baker PJ (2008). Deciduousness in a seasonal tropical forest in western Thailand: Interannual and intraspecific variation in timing, duration and environmental cues. Oecologia, 155, 571-582.

Woodward FI (1987). Climate and Plant Distribution. Cambridge University Press, Cambridge, UK.

Wu ZL (2000). Forest of China. China Forestry Publishing House, Beijing. (in Chinese) [吴中伦 (2000). 中国森林. 中国林业出版社, 北京.]

Wu ZY (1980). Chinese Vegetation. Science Press, Beijing. 279-306. (in Chinese) [吴征镒 (1980). 中国植被. 科学 出版社, 北京. 279-306.]

Wyka TP, Oleksyn J (2014). Photosynthetic ecophysiology of evergreen leaves in the woody angiosperms-A review. Dendrobiology, 72, 3-27.

Xiong XG, Xiong GM, Xie ZQ (2002). The regeneration of tree species in the mixed evergreen-deciduous broad-leaved forests in the Shennongjia Mountains, Hubei Province. Acta Ecologica Sinica, 22, 2001-2005. (in Chinese with English abstract) [熊小刚, 熊高明, 谢宗强 (2002). 神 农架地区常绿落叶阔叶混交林树种更新研究. 生态学 报, 22, 2001-2005.]
Yuan X, Ma KM, Wang D (2013). Optimal number of herb vegetation clusters: A case study on Yellow River Delta. Acta Ecologica Sinica, 33, 2514-2521. (in Chinese with English abstract) [袁秀, 马克明, 王德 (2013). 草地植 物群落最优分类数的确定一以黄河三角洲为例. 生态 学报, 33, 2514-2521.]

Zhang JT (1995). Quantitative Vegetation Ecology. Science and Technology Press of China, Beijing. (in Chinese) [张金屯 (1995). 植被数量生态学方法. 中国科学技术出版社, 北京.]

Zhang M, Xiong GM, Xie ZQ (2004). Ecological investigation of the mixed broad leaved deciduous and evergreen forest in Three Gorges Reservoir Area. Resources and Environment in the Yangtze Basin, 13, 168-173. (in Chinese with English abstract) [张烅, 熊高明, 谢宗强 (2004). 三峡 库区常绿落叶阔叶混交林的监测研究. 长江流域资源 与环境, 13, 168-173.]

Zhao LJ, Xiang WH, Li JX, Deng XW, Liu C (2013). Floristic composition, structure and phytogeographic characteristics in a Lithocarpus glaber-Cyclobalanopsis glauca forest community in the subtropical region. Scientia Silvae Sinicae, 49(12), 10-17. (in Chinese with English abstract) [ 赵 丽娟, 项文化, 李家湘, 邓湘雯, 刘聪 (2013). 中亚热 带石栋-青冈群落物种组成、结构及区系特征. 林业科 学, 49(12), 10-17.]

Zhou GY (1996). The deciduous broad-leaved forest of China-Also discussing about the belonging of the evergreen mixed deciduous broad-leaved forest. Journal of Ningbo University, 9(3), 93-102. (in Chinese with English abstract) [周光裕 (1996). 中国的落叶阔叶林一一兼论 常绿落叶阔叶混交林的归属问题. 宁波大学学报, 9(3), 93-102.]

特邀编委: 沈泽昊 责任编辑: 王 蒇

附录1 鄂西南星斗山和木林子自然保护区亚热带常绿落叶阔叶混交林各样地物种名录

Appendix 1 List of species of the subtropical evergreen-deciduous broadleaved mixed forest across two national nature reserves in Southwest Hubei, China http://www.plant-ecology.com/appendix/CJPE2015-10-A1.pdf 